\title{
Quick- and Slow-release Iron: A Double-blind Trial with a Single Daily Dose Regimen
}

\author{
SHEILA T. CALLENDER,* M.D., F.R.C.P.
}

Summary : In a double-blind trial the response to treat$S$ ment with Ferro-Gradumes (a slow-release preparation of ferrous sulphate) has been compared in the same individuals with the response to ferrous fumarate in a single daily dose regimen using a similar dose of iron. No significant difference was found in the therapeutic response or in the incidence of side-effects between the two preparations.

\section{Introduction}

Recent years have seen the production of various forms of slow-release iron preparations. It is claimed that such preparations produce fewer side-effects than the conventional forms of iron treatment, and that absorption is more efficient because the iron is released in the intestine. A clinical trial carried out by Israëls and Cook (1965) suggested that the therapeutic response to one tablet of Ferro-Gradumet (105 mg. of iron) daily was about the same as that obtained with one ferrous sulphate tablet (180 mg. of iron) taken three times a day after meals. Iron taken with food is only about half as well absorbed as when taken between meals (Brise and Hallberg, 1962), and it therefore seemed of interest to compare the response to a single daily dose of Ferro-Gradumet (a slow-release preparation of ferrous sulphate) with that obtained with a similar dose of a conventional iron preparation given once daily before breakfast.

${ }^{59} \mathrm{Fe}$-labelled therapeutic preparations of iron show great variation in absorption between individuals with comparable degrees of anaemia (Callender and Warner, 1969); the present study was therefore designed to compare the effect of the two iron preparations in the same individual.

\section{Materials and Methods}

Patients with untreated iron-deficiency anaemia were asked to take part in an investigation of some new forms of iron treatment. They were told that they would be required to attend at fortnightly intervals to have a blood count and to be supplied with tablets. Each subject was allotted three packets, A, B, and $C$, all containing 14 tablets. A and $C$ were either FerroGradumet or ferrous fumarate with a red film coating, very similar in appearance to that of Ferro-Gradumet. The ferrous fumarate provided $100 \mathrm{mg}$. of iron per tablet, and the FerroGradumet $105 \mathrm{mg}$. Packet B contained 14 placebo tablets, identical in appearance with ferrous fumarate. The two periods of iron treatment were therefore separated by two weeks of placebo treatment in every instance.

The majority of subjects were women in whom it was suspected that menorrhagia was causing their anaemia, and in these the trial was so arranged that the menstrual period fell within the placebo fortnight. The two weeks between active treatment allowed the serum iron to return to the initial low value and the blood count to stabilize again.

The patients were instructed to take one tablet first thing each morning before breakfast. The doctor in charge was not aware of the identity of the tablets in packets A or C.

* First Assistant, Nuffield Department of Clinical Medicine, Radcliffe D

\begin{abstract}
Results
The trial began with 30 subjects, but for various reasons full data were obtained in only 19 . One woman was admitted to hospital for gynaecological examination during the trial ; two were inadvertently given other iron therapy during the trial; two subjects each lost one packet of tablets ; four missed one or other of their appointments; and two discontinued treatment because of intolerance. The last-mentioned two declared that each tablet in turn, including the placebo, made them sick, and though they claimed to have made a real attempt to take the tablets they stopped taking them after one or two days.

Of the 19 who completed the trial the mean increase in haemoglobin during treatment with ferrous fumarate was $1.52 \mathrm{~g}$. in two weeks, and with Ferro-Gradumet 1.35 g. (see Table). The $t$ test for the paired observations in the individual subjects showed no significant difference in the response to the two preparations $(t=0.5324)$. Apart from the two subjects who discontinued treatment, none reported anything more than minor disturbance of bowel habit, and noted no difference between the treatment regimens.
\end{abstract}

Haemoglobin Levels in $\mathrm{g} . / 100 \mathrm{ml}$. at the Beginning and End of Each

\begin{tabular}{|c|c|c|c|c|c|c|}
\hline \multirow{2}{*}{$\begin{array}{l}\text { Case } \\
\text { No. }\end{array}$} & \multicolumn{3}{|c|}{ Ferro-Gradumet } & \multicolumn{3}{|c|}{ Ferrous Fumarate } \\
\hline & $\mathrm{Hb} 1$ & $\mathrm{Hb} 2$ & Difference & Hb 1 & $\mathrm{Hb} 2$ & Difference \\
\hline $\begin{array}{r}3 \\
5 \\
7 \\
8 \\
10 \\
14 \\
15 \\
16 \\
17 \\
18 \\
19 \\
20 \\
21 \\
22 \\
23 \\
24 \\
25 \\
27 \\
30\end{array}$ & $\begin{array}{r}11.8 \\
6.8 \\
9.0 \\
11.4 \\
8.1 \\
10.1 \\
12.3 \\
8.6 \\
9.0 \\
9.4 \\
12.3 \\
9.4 \\
9.7 \\
7.8 \\
10.7 \\
8.6 \\
11.4 \\
6.2 \\
8.9\end{array}$ & $\begin{array}{r}12.7 \\
8.9 \\
10.1 \\
12.0 \\
9.2 \\
12.0 \\
13.5 \\
8.9 \\
9.1 \\
11.2 \\
12.3 \\
10.3 \\
11.8 \\
10.4 \\
11.7 \\
13.2 \\
12.1 \\
8.3 \\
9.5\end{array}$ & $\begin{array}{l}0.9 \\
2.1 \\
1.1 \\
0.6 \\
1.1 \\
1.9 \\
1.2 \\
0.3 \\
0.1 \\
1.8 \\
0.0 \\
0.9 \\
2.1 \\
2.6 \\
1.0 \\
4.6 \\
0.7 \\
2.1 \\
0.6\end{array}$ & $\begin{array}{r}12.3 \\
9.0 \\
10.1 \\
6.8 \\
8.1 \\
8.0 \\
10.3 \\
7.7 \\
9.1 \\
12.4 \\
9.7 \\
7 \cdot 2 \\
7.4 \\
11.1 \\
9.5 \\
7.0 \\
9.8 \\
9.5 \\
8.9\end{array}$ & $\begin{array}{r}14.0 \\
9.5 \\
10.4 \\
9.4 \\
8.3 \\
10.4 \\
12.9 \\
8.2 \\
10.8 \\
14.5 \\
11.6 \\
8.6 \\
9 \cdot 2 \\
12.0 \\
11.0 \\
8.0 \\
11.4 \\
13.2 \\
9.5\end{array}$ & $\begin{array}{l}1.7 \\
0.5 \\
0.3 \\
2.6 \\
0.2 \\
2.4 \\
2.6 \\
0.5 \\
1.7 \\
2.1 \\
1.9 \\
1.4 \\
1.8 \\
0.9 \\
1.5 \\
1.0 \\
1.6 \\
3.7 \\
0.6\end{array}$ \\
\hline Mean & & & 1.35 & & & 1.52 \\
\hline
\end{tabular}

\section{Discussion}

That only two-thirds of the subjects completed the full trial satisfactorily indicates the difficulty in obtaining properly controlled observations of the response to iron treatment. From the 19 who did complete the test it appears that $100 \mathrm{mg}$. of iron as a single daily dose of ferrous fumarate is as effective as the slow-release type of iron, Ferro-Gradumet, and in these subjects it did not produce any greater side-effects.

In other studies in which fewer side-effects have been noted with slow-release iron than with conventional iron therapy the comparison has been made with a thrice-daily regimen in different subjects (Ziehm and Likos, 1966 ; Gomez and Gomez, 1967). The extremely high instance of over $70 \%$ of side-effects from the use of ferrous sulphate reported by Gomez and Gomez is very different from the $20-30 \%$ found by Hallberg and Sölvell (1966) in their careful double-blind trials in a total of 
over 2,000 subjects. Webster (1962) reported more side-effects from ferrous sulphate taken twice a day than from a similar dose of slow-release ferrous sulphate also taken twice a day. Almost half the subjects he was studying, however, suffered from gastrointestinal irritation or ulcerative colitis, and it is difficult to judge how many of the symptoms were due to underlying disease rather than the iron therapy.

In studies in which radioactive iron has been used to investigate the absorption from slow-release preparations (Bothwell, Pirzio-Biroli, and Finch, 1958 ; Crossland-Taylor, Keeling, and Cromie, 1965) the latter have been shown to be less well absorbed than similar doses of ordinary ferrous sulphate. There is little justification, therefore, for expecting slow-release iron to be more effective in therapy.

The idea of being able to treat patients with a single daily dose is attractive, but it would appear from the present data that no specific benefit is to be derived by using a slow-release preparation.

Ferrous fumarate is less soluble than ferrous sulphate, and in a recent study with ${ }^{59} \mathrm{Fe}$-labelled pills (Callender and Warner, 1969) it was less well absorbed. This would account for the fact that the therapeutic response of the fumarate is similar to that of slow-release ferrous sulphate. A similar daily dose of quickly released ferrous sulphate would be expected to give a better response.

I am grateful to Dr. Violet Anderson, formerly of Glaxo Laboratories, for the supply of coded tablets.

\section{REFERENCES}

Bothwell, T. H., Pirzio-Biroli, G., and Finch, C. A. (1958). Fournal of Laboratory and Clinical Medicine, 51, 24.

Brise, H., and Hallberg, L. (1962). Acta Medica Scandinavica, Suppl. No. 376, p. 59.

Callender, S. T., and Warner, G. T. (1969). British Medical fournal, 4, 532 .

Crossland-Taylor, P., Keeling, D. H., and Cromie, B. W. (1965). Current Therapeutic Research, Clinical and Experimental, 7, 244. Gomez, G. and Gomez, J. (1967). British fournal of Clinical Practice, 21,31 .

Hallberg, L., and Sölvell, L. (1966). Acta Medica Scandinavica, Suppl.

No. 459, p. 23. .

Webster, J. J. (1962). Current Therapeutic Research, Clinical and Experimental, 4, 130

Ziehm, D. J., and Likos, J. (1966). Obstetrics and Gynecology, 28, 430.

\title{
Absorption of Therapeutic Preparations of Iron Measured with a Whole Body Counter
}

\author{
SHEILA T. CALLENDER,* M.D., F.R.C.P. ; G. T. WARNER, † D.PHIL.
}

Cummary : The Oxford Whole Body Counter was used ummary : The Oxford Whole Body Counter was used
to measure absorption from various therapeutic preparations of iron in five groups of subjects. Succinic acid enhanced absorption of iron when added to a solution of ferrous fumarate, but not when given with tablets of ferrous fumarate or ferrous sulphate. Ferrous fumarate plus ascorbic acid was absorbed better than ferrous fumarate alone but no better than ferrous sulphate. The addition of ascorbic acid and succinic acid to tablets of ferrous sulphate did not enhance absorption significantly.

\section{Introduction}

Iron-deficiency anaemia is a common condition throughout the world and ferrous sulphate has proved a cheap and effective form of therapy. Nevertheless, new preparations of iron are constantly appearing on the market backed by recommendations which often have not very good foundation. We have used the Oxford Total Body Counter (Warner and Oliver, 1966) to compare the absorption of iron from different therapeutic preparations in individual subjects, and this paper reports our results.

\section{Materials and Methods}

The use of the counter in studies of absorption has been reported elsewhere (Callender, Witts, Warner, and Oliver, 1966).

Forty-four subjects, divided into five groups, were selected for the investigation. The purpose of the study was fully explained to each subject and all agreed to take part. Three subjects were members of the hospital staff and were initially considered to be normal, but one was found to have a serum iron of only $32 \mu \mathrm{g} . / 100 \mathrm{ml}$. The remaining 41 were patients with untreated or partially treated iron deficiency. None had received iron therapy for at least two weeks before the test. In all except six the haemoglobin was $10 \mathrm{~g}$. or more. Groups 1, 2, 3, and 5 (see below) were roughly similar with regard to the degree of anaemia and iron deficiency; the mean haemoglobin values were $11.8,11.7,11.9$, and $11.7 \mathrm{~g} . / 100 \mathrm{ml}$. respectively, and the mean serum iron 46 , 36,46 , and $50 \mu \mathrm{g} . / 100 \mathrm{ml}$. respectively. Subjects in group 4 were on the whole less anaemic and less iron-deficient ; mean haemoglobin $13.8 \mathrm{~g} . / 100 \mathrm{ml}$. and mean serum iron $88 \mu \mathrm{g} . /$ $100 \mathrm{ml}$. (Fig. 1).

Because of the great variability of absorption in different subjects two, or in some instances three, preparations were compared in the same individual by sequential tests, the order of tests being randomized. The total radioactivity retained by any one subject was never more than $0.5 \mu \mathrm{Ci}$.

The subjects were divided into the following groups:

Group 1.-Eight subjects. Iron absorption from a 5 - $\mathrm{ml}$. dose of a syrup containing $140 \mathrm{mg}$. of ferrous fumarate was compared with that from a similar preparation of ferrous fumarate plus $210 \mathrm{mg}$. of succinic acid. Each dose contained $45 \mathrm{mg}$. of iron.

Group 2.-Nine subjects. Iron absorption from a tablet containing $200 \mathrm{mg}$. of ferrous fumarate was compared with that from a similar tablet incorporating $200 \mathrm{mg}$. of succinic acid. The dose of iron was $65 \mathrm{mg}$.

Group 3.-Nine subjects. Iron absorption was compared from three different types of tablet: $200 \mathrm{mg}$. of ferrous fumarate, $185 \mathrm{mg}$. 